Case Report

\title{
A Man with Unilateral Endophthalmitis: A Case of Disseminated Nocardiosis
}

\author{
N. Navarrete-Navarrete, ${ }^{1}$ J. Escobar Sevilla, ${ }^{2}$ M. Toribio García, ${ }^{3}$ F. Urbano, ${ }^{3}$ \\ J. M. Sabio, ${ }^{1}$ and J. Jiménez-Alonso ${ }^{1}$ \\ ${ }^{1}$ Unit of Autoimmune Diseases, Service of Internal Medicine, University Hospital Virgen de las Nieves, \\ Avenida Fuerzas Armadas 2, 18014 Granada, Spain \\ ${ }^{2}$ Service of Internal Medicine, University Hospital Virgen de las Nieves, Avenida Fuerzas Armadas 2, 18014 Granada, Spain \\ ${ }^{3}$ Service of Ophthalmology, University Hospital Virgen de las Nieves, Avenida Fuerzas Armadas 2, 18014 Granada, Spain
}

Correspondence should be addressed to N. Navarrete-Navarrete; nurianavarreten@gmail.com

Received 30 November 2014; Accepted 5 March 2015

Academic Editor: Gernot Walder

Copyright (C) 2015 N. Navarrete-Navarrete et al. This is an open access article distributed under the Creative Commons Attribution License, which permits unrestricted use, distribution, and reproduction in any medium, provided the original work is properly cited.

We present the case of a patient with an infection by Nocardia which manifested itself with monocular endophthalmitis. Nocardia infection is not common and ocular involvement is one of the most uncommon presentations. In these cases it is very important to make an early diagnosis and intensive treatment to prevent the visual prognosis.

\section{Introduction}

Painful red eye is one of the diseases most common in ophthalmology services. Its etiological study should consider infectious, inflammatory, and paraneoplasic causes, although in a nonnegligible number of cases the cause is unknown. We present a patient consulting by painful red eye, as a rare presentation of an uncommon systemic infection.

\section{Case History}

A 60-year-old male with no relevant past medical history complained of intense pain, reduced visual acuity, and reddening of the left eye that had lasted a week and had not improved despite treatment with topical anti-inflammatories. He was examined by an ophthalmologist and diagnosed with acute unilateral panuveitis in the left eye and initiated treatment with prednisone $60 \mathrm{mg}$ /day but still observed no improvement.

A dry cough lasting several months, loss of appetite, and weight loss of $2 \mathrm{~kg}$ in the previous 2 months stood out in the patient's medical history.

During the ophthalmological examination the Tyndall effect was particularly evident without hypopyon.
Conjunctival hyperaemia and rubeosis iridis were observed and IOP was $18 \mathrm{mmHg}$.

In the general physical examination dispersed rhonchi sounds were detected in both hemithoraces and mild pain during palpation of the right hypochondrium was observed. The liver was not enlarged and there were no other significant findings. The rest of the physical examination was normal.

Ophthalmological progress was slow due to the presence of progressive erythema and orbital swelling of the left eye and an increase in IOP of the left eye. The patient also presented with deteriorated breathing, a persistent dry cough, and breathlessness after minimal exertion. He was administered parenteral antibiotics (ceftriaxone) and treatment for ocular hypertension and was admitted into hospital.

The blood tests were normal and the biochemistry showed CRP $11 \mathrm{mg} / \mathrm{dL}$, and the rest of the parameters were normal. The following tests were normal or negative: serological testing for cytomegalovirus and herpes virus, hepatitis B and C, toxoplasma, HIV, syphilis, and tuberculin skin test.

An abdominal ultrasound showed several small hypodense lesions compatible with cysts and the chest and abdomen CT highlighted irregular, alveolar-shaped pseudonodules measuring $20 \times 17 \mathrm{~mm}$ and $10 \times 19 \mathrm{~mm}$ in the left lower lobe (see Figure 1). 

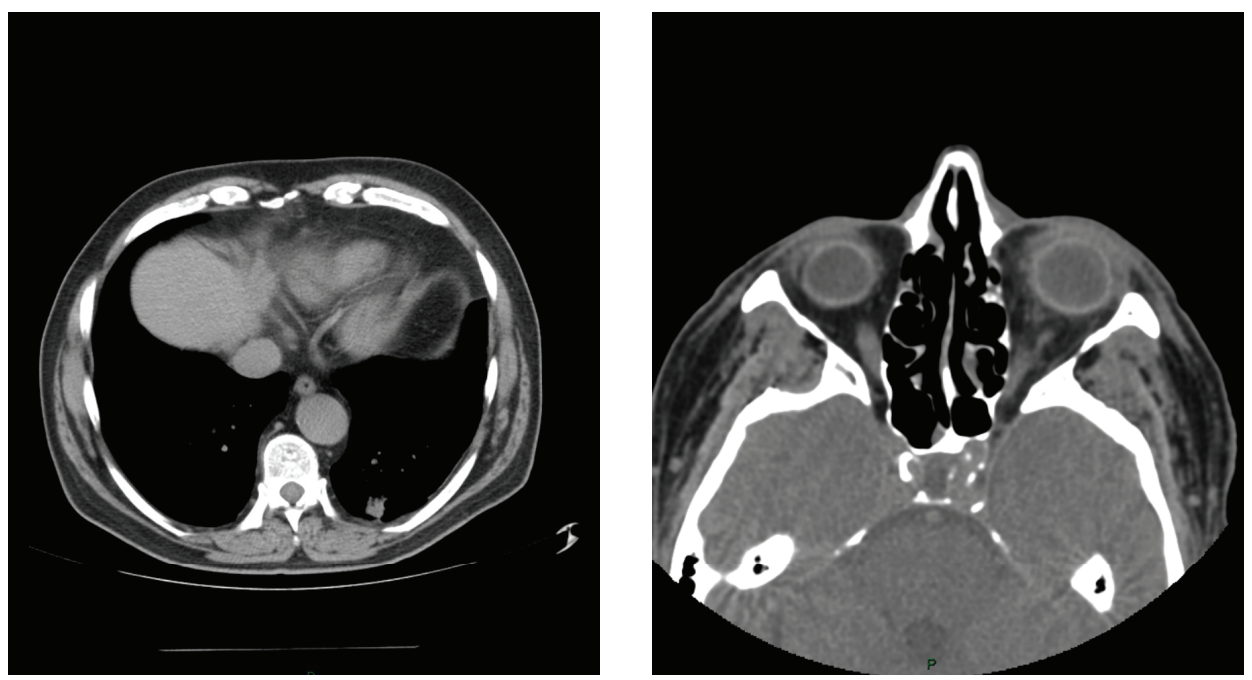

FIgure 1: Orbital and lung CT scan.

A bronchoscopy with bronchoalveolar lavage was performed and there were no microbiological or cytological findings.

Given the absence of an aetiological diagnosis, a vitrectomy was performed and the growth of Nocardia otitidiscaviarum resistant to imipenem, tetracyclines, clarithromycin, amoxicillin, and cefotaxime and susceptible to TMP-SMX was detected. Therapy with TMP-SMX was initiated, leading to ophthalmological and respiratory improvement. After 2 months, both the ocular inflammation and the liver and lung lesions had disappeared, as shown by the imaging tests.

\section{Discussion}

Nocardia spp. infection is caused by a slow-growing, aerobic, Gram-positive microorganism that is inhaled from organic matter or aerosolized water.

In general, nocardia infections of the eye are very uncommon, especially in nonimmunosuppressed patients $[1,2]$.

Cases of endophthalmitis described in the literature have been linked to infection after surgery or trauma [3], which was not the case for our patient.

In cases of systemic infection, the mortality rate can be as high as $15 \%$ [4], which is why early antibacterial treatment is crucial. Furthermore, treatment should be adjusted to take into account the in vitro sensitivity and resistance profile.

Atypical presentations of nocardia should be considered in patients presenting with endophthalmitis and other systemic symptoms.

\section{Conflict of Interests}

All authors confirm that they are not involved in any organization or entity with a financial interest in or financial conflict with the subject matter or materials discussed in this paper.

\section{References}

[1] T. C. Sorrel, D. H. Mitchell, J. R. Iredell, and S. C.-A. Chen, "Nocardia species," in Principles and Practice of Infectious Diseases, G. L. Mandell, J. E. Bennett, and R. Dolin, Eds., p. 3199, Churchill Livingstone Elsevier, Philadelphia, Pa, USA, 7th edition, 2010.

[2] E. W. M. Ng, I. E. Zimmer-Galler, and W. R. Green, "Endogenous Nocardia asteroides endophthalmitis," Archives of Ophthalmology, vol. 120, no. 2, pp. 210-213, 2002.

[3] A. Haripriya, P. Lalitha, M. Mathen et al., "Nocardia endophthalmitis after cataract surgery: clinicomicrobiological study," American Journal of Ophthalmology, vol. 139, no. 5, pp. 837-846, 2005.

[4] M. F. Yang, M. Xu, W. Wei et al., "Clinical findings of 40 patients with nocardiosis: a retrospective analysis in a tertiary hospital," Experimental and Therapeutic Medicine, vol. 8, no. 1, pp. 25-30, 2014. 


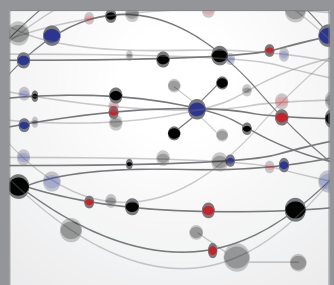

The Scientific World Journal
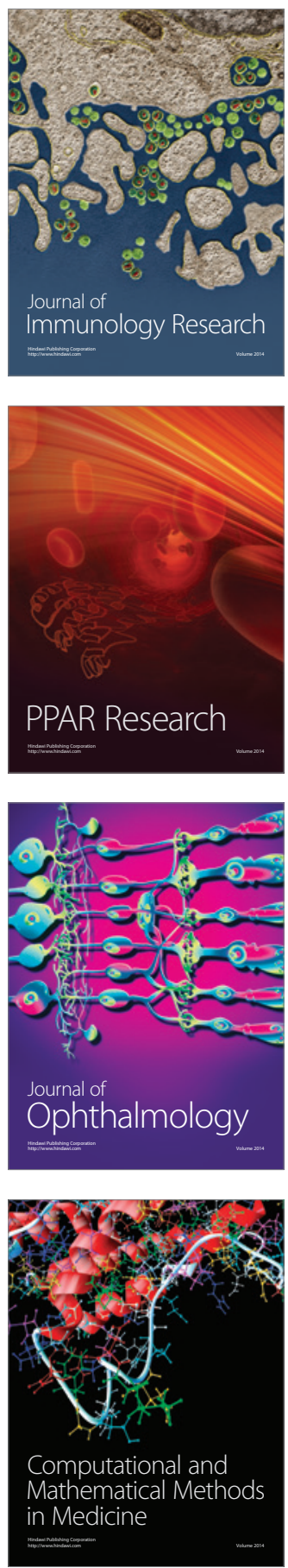

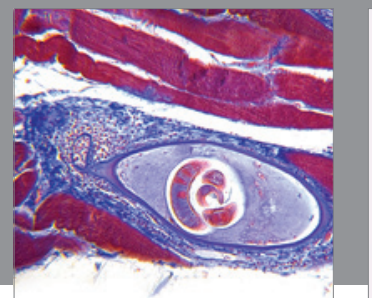

Gastroenterology

Research and Practice
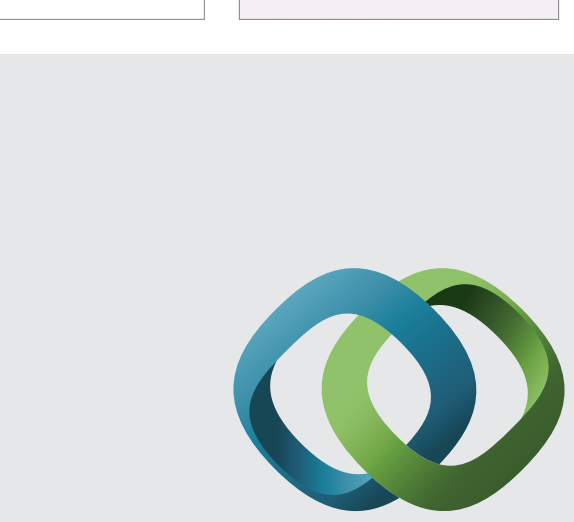

\section{Hindawi}

Submit your manuscripts at

http://www.hindawi.com
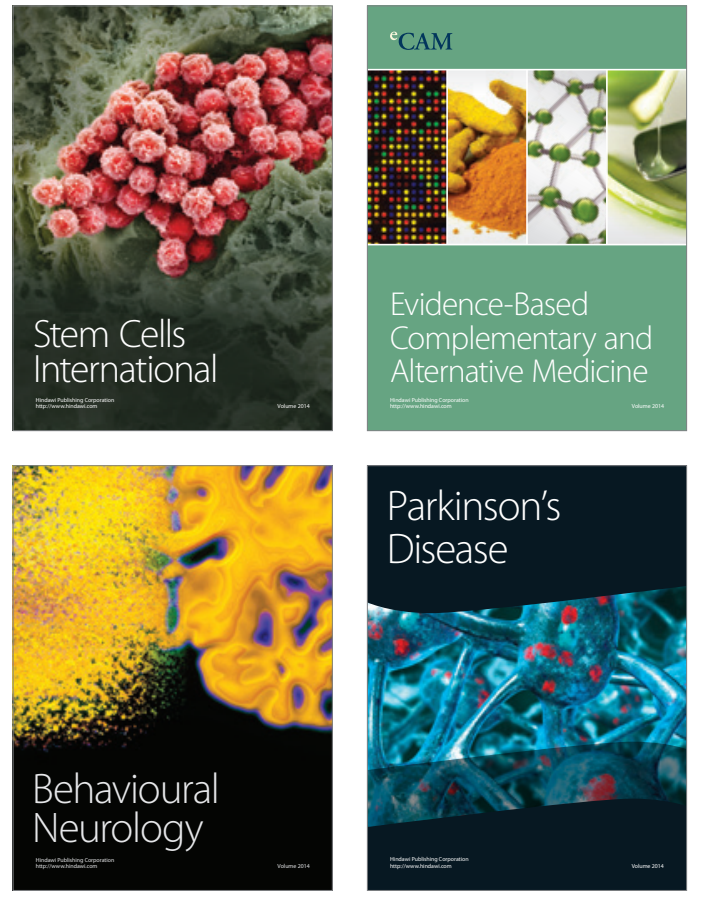
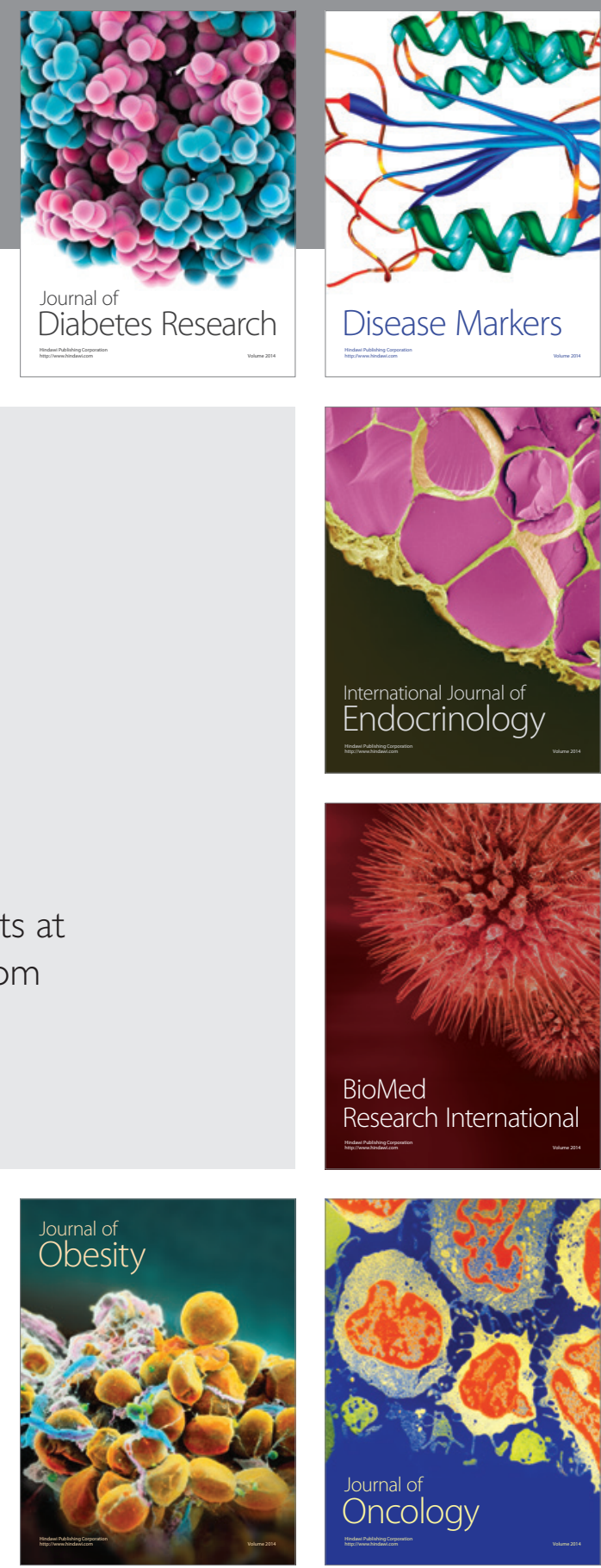

Disease Markers
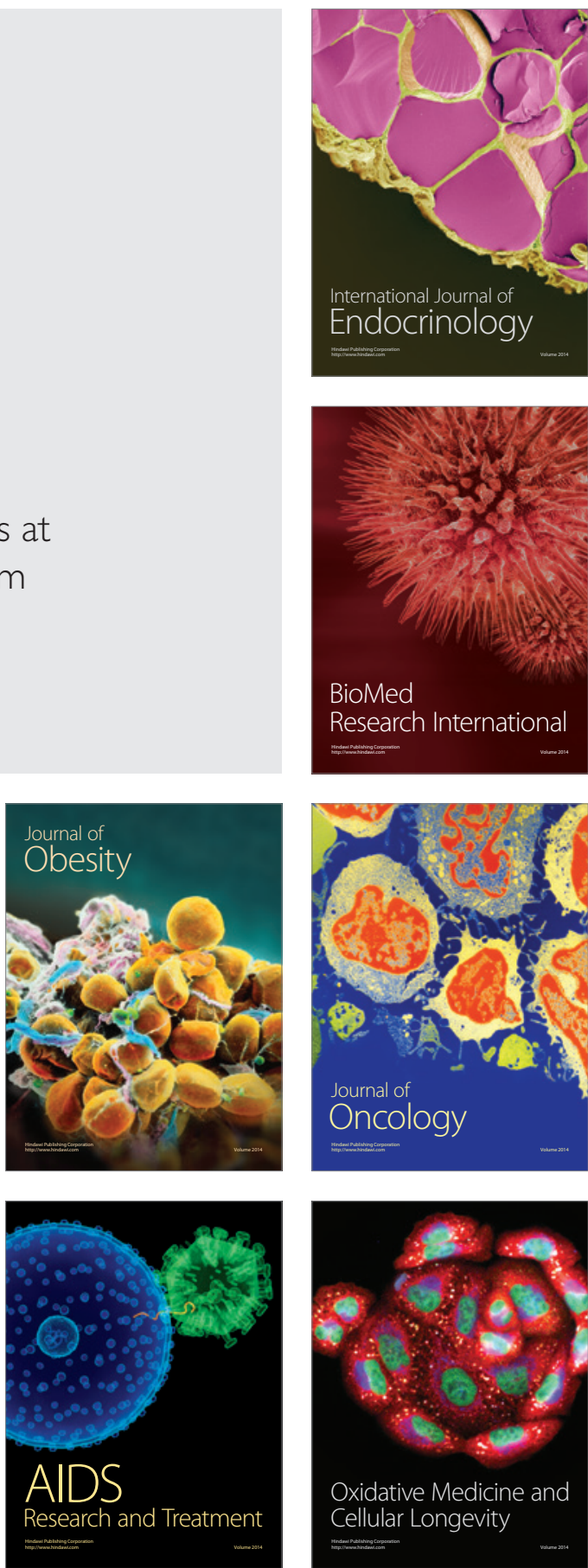